\title{
Transcription Initiation
}

National Cancer Institute

\section{Source}

National Cancer Institute. Transcription Initiation. NCI Thesaurus. Code C20147.

Transcription Initiation involves RNA polymerase (and usually other factors) binding at a specific gene promoter DNA site followed by local DNA unwinding and inauguration of the 5-prime to 3-prime biosynthesis of an RNA transcript complementary to the DNA template. 